\title{
UNEMPLOYMENT DURATION: EVIDENCE FROM THE HOUSEHOLD LABOUR FORCE SURVEY
}

\author{
David Grimmond \\ New Zealand Institute of Economic Research
}

Over the last two decades there has been an increasing awareness of a dynamic view of labour markets. For example, in a study of labour market flows in the US, Perry (1972) noted that labour force groups that typically experienced high unemployment rates tended to also experience frequent transitions in and out of unemployment. This type of evidence changed perceptions of unemployment from that of a stagnant pool of job seekers awaiting a business upturn, to one where unemployment was the result of imbalances in the frequent movement of people in and out of unemployment. This view was disputed by evidence produced by Clark and Summers (1979) which suggested that although a large proportion of the labour market clears, high unemployment tends to result from a relatively small number of workers who remain out of work for a large part of the time. The experience of persistent unemployment in many industrial nations since the late 1970s and the concentration of much of this unemployment among a relatively small but persistently unemployed group tends to back the Clark and Summers view of labour market dynamics.

Analysis of the likely experience of the unemployed is important in assessing how serious the costs from unemployment will be on society. For a given level of unemployment, the greater the concentration of the unemployed who remain so for long periods, the greater the likelihood of developing highly disadvantaged sectors of society. Long unemployment spells might lower employment prospects for the individual and lack of skill maintenance will reduce productivity once a job is found. Other costs to society may manifest themselves in the form of increased crime (requiring increased resources devoted to prevention, detection, the legal process, punishment and rehabilitation) and lower labour market participation in the next generation. The nature of unemployment patterns will also influence the appropriateness and success of policies aimed at lowering the costs of unemployment.

However, little is known of the labour market dynamics in New Zealand. Research on labour market dynamics in New Zealand has been limited mainly due to data limitations. For example, studies such as Morrison (1989) and Dasgupta (1991) had to rely on either inter-censal comparisons or data from the Department of Labour's unemployment register. Both have their limitations, despite the comprehensive coverage of census data, the five year gap between census surveys means they can not provide much information about the process of change; and many problems have been noted on the reliability of the unemployment register data, including: potential delays of entry due to the voluntary nature of registration, and the likelihood that the timing of de-registration was often influenced by the administration of the register.

The introduction of the quarterly Household Labour Force Survey (HLFS) in December 1985 has greatly increased information on the New Zealand labour market. By surveying individuals for eight consecutive quarters, it is possible to map their labour market experience for this period. With a representative sample of the New Zealand working age population (those aged 15 years and older), one is able to obtain a view of changes in labour force status (employed, unemployed, or outside the labour force) both for the economy as a whole and for segments of the economy. Although there are a number of limitations with this data (as discussed in Grimmond, 1992), data derived from the HLFS has the potential of greatly increasing our knowledge of New Zealand labour market dynamics.

\section{Unemployment duration}

The present study is made under the premise that the costs imposed on society from a given level of unemployment are influenced by the degree to which this unemployment is involuntary and the length of unemployment spells. That is, changes in the composition of unemployment may have as much influence on the economic costs of unemployment as changes in its level. It is beyond the scope of the present to measure the economic costs of unemployment. Instead we propose to test for a relationship between unemployment duration and the ability of individuals to leave unemployment. For example, if the probability of leaving unemployment for a job declines the longer one has already been unemployed, then this could be taken as evidence in support of the Clark and Summers (1979) hypothesis that a concentrated group of persistently unemployed are a large proportion of unemployment. The evidence presented here supports this view, but doubt remains as no allowance is made for other influencing factors.

We concentrate on duration for three reasons:

- there is little scope to obtain meaningful data on the voluntary nature of unemployment, 
- length of unemployment spell is likely to impose its own costs independent of how voluntary it is, and

-the probability that an unemployment spell is involuntary is likely to increase with the length of the spell. $^{2}$

Unemployment in New Zealand increased strongly over the study period from $4.2 \%$ of the labour force in March 1986 to $10.1 \%$ by June 1991 . Looking at men only the increase was even more marked from $3.6 \%$ in March 1986 to $10.5 \%$ in June 1991 . As might be expected from such a large increase in unemployment, evidence from unemployment duration data suggests that a large proportion of this increased unemployment was not voluntary. The long term unemployed (defined here as unemployment spells of over six months duration) as a proportion of total unemployment also doubled in the six year period 1986-91 from $22.0 \%$ of tofal unemployment in 1986 to $45.1 \%$ in 1991 (see Table 1). This trend has been similar for both males and females, though slightly stronger for males.

By 1991 almost half the men recorded as unemployed had been unemployed for over six months. Accounting for the length of time spent unemployed, the importance of the long term unemployed as a ratio of total time spent unemployed is further highlighted. In 1991 around $80 \%$ of the total worker days lost due to unemployment is estimated to have come from those unemployed for periods in excess of six months (see Table 1). Even in 1986, when the percentage of long term unemployed was considerably lower, the long term unemployed accounted for nearly $65 \%$ of production days lost due to unemployment. So although the long term unemployed may only account for a minority of the individuals unemployed at any one time, they usually account for the majority of worker days lost through unemployment and hence also the majority of the costs to society associated with unemployment.

\section{Leaving unemployment}

Examination of the relationship between unemployment duration and the probability of exit from unemployed is made with the use of hazard functions. Although hazard functions can be used with increasing levels of sophistication (see for example Keifer, 1988 or Narendranathan and Stewart, 1989) the approach used here is quite simple. The approach reflects the limited number of observations available in the current study. which could undermine the reliability of more complex approaches. The risk in using a simple approach is that by neglecting other factors we may overstate the relitkmship between duration and the probability of ex/l from unemployment. The results presented here should therefore be viewed as just an initial examination with largely illustrative value and should not be regarded as providıng accurate quantitative measures.

Following the example of Hasan and de Broucker (1982) our aim is to establish whether the probability of exit from unemployment is a function of duration in unemployment. Given duration data availability disaggregations are made only by gender. Exit from unemployment is assumed to imply a shift to employment (E), to the periphery of the labour force $(P)$ or exit from the labour force $(\mathrm{N})$. Therefore for each category (male, female

Table 1 . Importance of the long term unemployed to total unemployment

\begin{tabular}{lccccccc} 
& 1986 & 1987 & 1988 & 1989 & 1990 & 1991 & $\begin{array}{c}\text { Averag } \\
1986-91\end{array}$ \\
& \multicolumn{7}{c}{ Percent of unemployed numbers unemployed for over six month } \\
& 23.5 & 30.3 & 35.9 & 41.1 & 44.0 & 49.5 & 38.0 \\
Male & 20.4 & 24.1 & 26.9 & 30.2 & 32.5 & 38.2 & 29.2 \\
Female & 22.0 & 27.6 & 32.2 & 36.6 & 39.5 & 45.1 & 34.4 \\
Total & & & & & & &
\end{tabular}

Percent of total time spent unemployed by those unemployed for over six months ${ }^{2}$

$\begin{array}{llllllll}\text { Male } & 63.5 & 71.8 & 76.4 & 80.4 & 82.3 & 84.4 & 76.8 \\ \text { Female } & 63.6 & 66.6 & 70.2 & 73.3 & 75.6 & 78.5 & 71.7 \\ \text { Total } & 63.7 & 69.8 & 74.2 & 78.0 & 80.1 & 82.4 & 75.1\end{array}$

Source: Estimated by author from HLFS data

Notes: $\quad 1$. Percentages are taken from totals excluding those who have not specified their duration of unemployment. This implicitly assumes that the distribution of unemployment duration for those not specified is the same as for those who have specified their unemployment duration.

2. Time spent unemployed calculated as the product of numbers in each unemployment duration category (0-1, 1-2, 2-3, 3-6, 6-12 and >12 months) and the mid-point of each duration category. e.g. 10,000 in the $0-1$ month category would be calculated as 5,000 person months of unemployment. For the open ended category the average is assumed to be 18 months. 
and total) there are three dependent variables ue, up and un: the probability of exit from unemployment toemployment, to the labour force periphery and outside the labour force respectively.

The data is sourced from the Department of Statistics' Household Labour Force Survey (HLFS). This is a quarterly interview survey of a sample of New Zealand households. Households are sampled on a statistically representative random basis from the rural and urban areas throughout the North and South Islands. The survey samples from the working age population defined as the total usually-resident, non-institutionalised, civilian population of New Zealand aged 15 years and over.

From this survey individuals can be designated into three employment status: employed, unemployed and not in the labour force. Employment status is defined as follows:

Employed: in the reference week worked for one hour or more for pay or profit; worked without pay for one hour or more in work which contributed directly to the operation of a business owned or operated by a relative; had a job but were not at work due to some extenuating factor such as illness, leave or an industrial dispute.

Unemployed: in the reference week were not employed, were available for work and had either actively sought work in the past four weeks ending with the reference week or had a new job to start within four weeks of the survey.

Not in the Labour Force: any person in the working age population who is neither employed or unemployed.
These definitions conform closely to the international standards specified by the International Labour Organisation. This allows international comparisons using this data to be relatively meaningful. It also means that the definition of unemployment is quite strict. For example perusing jobadvertisements in newspapers is not considered to be actively seeking work. The HLFS does allow an examination of those not strictly unemployed but on the periphery of the labour force. We can define the peripheral labour force as including those who are actively seeking work, but not currently available for work and those available but not actively seeking. 4

\section{Variables and method}

The dependent variables are calculated by matching respondents between surveys so that flows between different employment status can be measured. These gross flows can then be used to calculate the probability of an individual changing employment status between surveys. These transition probabilities are the dependent variables used in the analysis that follows.

The explanatory variable used is a median measure of unemployment duration (M) calculated from the recall unemployment duration data published in The New Zealand Labour Force. The method developed by Kay (1982) for calculating the median measure of capacity utilisation from the NZIER's Quarterly Survey of Business Opinion was used to calculate median duration measures:

median $=\begin{aligned} & \text { lower limit of } \\ & \text { median interval }\end{aligned}+\left|\begin{array}{ll}\begin{array}{l}\text { number below } \\ \text { median interval }\end{array} \\ \begin{array}{l}\text { number within } \\ \text { median interval }\end{array}\end{array}\right| \times \begin{aligned} & \text { width of } \\ & \text { median } \\ & \text { interval }\end{aligned}$

Figure 1. Median unemployment duration

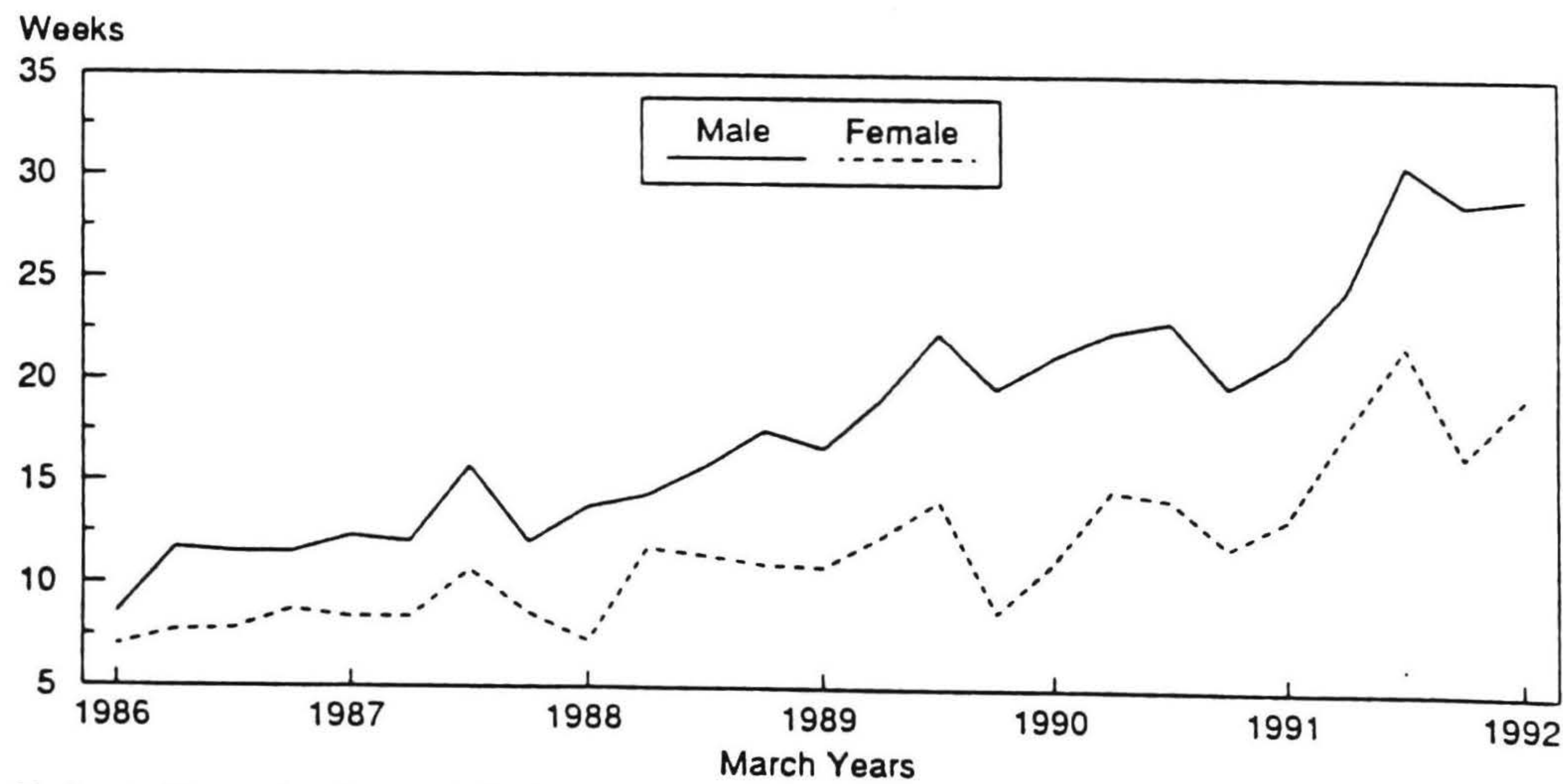

Estimated by author from HLFS data 
Table 2 Preferred hazard functions, 1986.1 - 1991.1

\begin{tabular}{|c|c|c|c|c|c|}
\hline \multirow[t]{3}{*}{ MALE } & $u e=$ & $\begin{array}{l}0.9498^{*} \\
(0.1562)\end{array}$ & 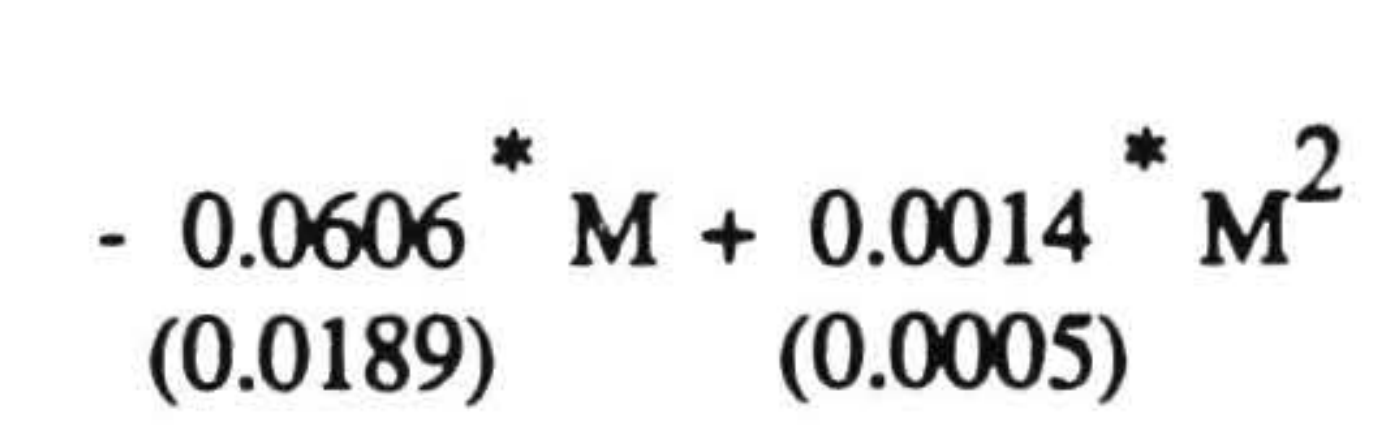 & $\begin{array}{l}\mathrm{R}^{2} \\
0.785\end{array}$ & $\begin{array}{l}\text { DW } \\
1.753\end{array}$ \\
\hline & $u p=$ & $\begin{array}{c}0.0237 \\
(0.0157)\end{array}$ & $\begin{array}{c}+0.0020^{*} \mathrm{M} \\
(0.0009)\end{array}$ & 0.165 & 1.300 \\
\hline & $u n=$ & $\begin{array}{l}0.3967^{*} \\
(0.0818)\end{array}$ & $\begin{array}{l}-0.0853^{*} \log (\mathrm{M}) \\
(0.0290)\end{array}$ & 0.276 & 2.397 \\
\hline \multirow[t]{3}{*}{ FEMALE } & $u e=$ & $\begin{array}{l}0.7087^{*} \\
(0.1154)\end{array}$ & $\begin{array}{l}-0.1512^{*} \log (\mathrm{M}) \\
(0.0485)\end{array}$ & 0.304 & 1.602 \\
\hline & $u p=$ & $\begin{array}{c}0.0392 \\
(0.0221)\end{array}$ & $\begin{array}{c}+0.0047^{*} \mathrm{M} \\
(0.0019)\end{array}$ & 0.191 & 2.172 \\
\hline & $u n=$ & $\begin{array}{l}0.3273^{*} \\
(0.0303)\end{array}$ & $\begin{array}{l}-0.0062^{*} \mathrm{M} \\
(0.0027)\end{array}$ & 0.179 & 1.825 \\
\hline \multirow[t]{3}{*}{ TOTAL } & $u e=$ & $\begin{array}{l}0.8971^{*} \\
(0.1519)\end{array}$ & 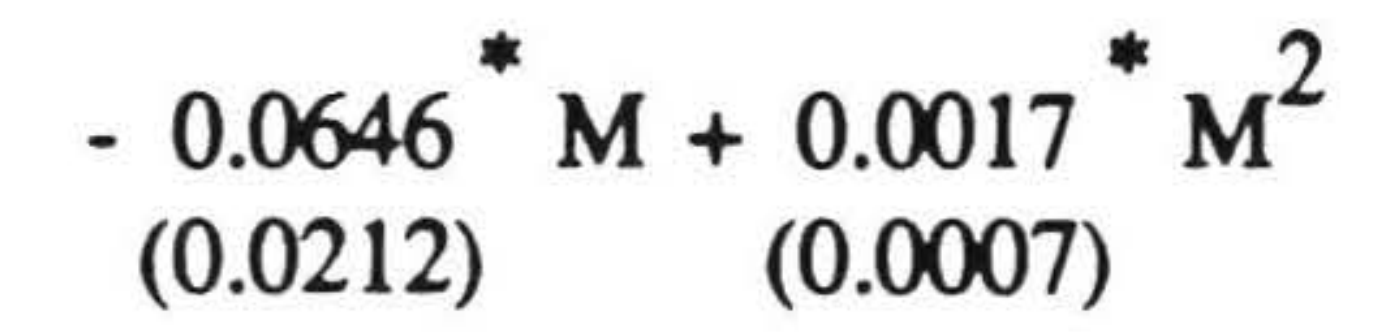 & 0.691 & 2.073 \\
\hline & $u p=$ & $\begin{array}{l}0.0266^{*} \\
(0.0133)\end{array}$ & $\begin{array}{c}+0.0032^{*} \mathrm{M} \\
(0.0009)\end{array}$ & 0.361 & 1.384 \\
\hline & $u n=$ & $\begin{array}{l}0.2871^{*} \\
(0.0224)\end{array}$ & $\begin{array}{c}-0.0060^{*} \mathrm{M} \\
(0.0015)\end{array}$ & 0.419 & 2.320 \\
\hline
\end{tabular}

Standard errors in brackets, * indicates significant at the $95 \%$ level of confidence, $M$ is the median measure of unemployment duration

The advantage of this method is that, except for the median interval, it does not require assumptions about the distribution of individuals within duration intervals necessary to estimate the mean. This is particularly a problem when dealing with the open ended interval (greater than one year) which does not enter the median calculation. This computational simplicity may also be regarded as a fault as a median measure ignores the informational content of the spread of individuals accross the duration intervals.

The median duration levels of unemployment for males and females are presented in Figure 1 (the total measure is merely a weighted average lying between the two graphed series). As could be expected from the data presented in Table 1, there has been a steady increase in the median duration of unemployment over the study period, and that duration of male unemployment has tended to be longer than that experienced by females.

A number of different functional forms were tested for each equation and the preferred hazard functions are presented in Table 2. The preference criteria were based simply on goodness of fit (adjusted $R^{2}$ ) and variable significance. The functional forms tested were not exhaustive, but the direction of relationships were robust between functional forms. That is, if the preferred equations exhibited a positive relationship between duration and probability of exit, then so too did the rejected functional forms but with lower explanatory power.

\section{Results}

A significant relationship between duration and probability of exit from unemployment was found for all nine combinations. The strength of the relationships appear to differ markedly and are not all linear. The relationship of unemployment duration with ue, the probability of moving into employment, appears to be the strongest, followed by un, the probability of leaving the labour force. In both these cases the relationship seems to be stronger with men than with women. Unemployment duration and the probability of moving to the labour force periphery are more closely related with women than men.

To aid interpretation the preferred male and female hazard function relationships have been graphed in Figures 2 - 4.5 Some caution is required when interpreting these results. Although the hazard functions indicate a correlation 
Figure 2.Probability of exit from unemployment to employment hazard functions

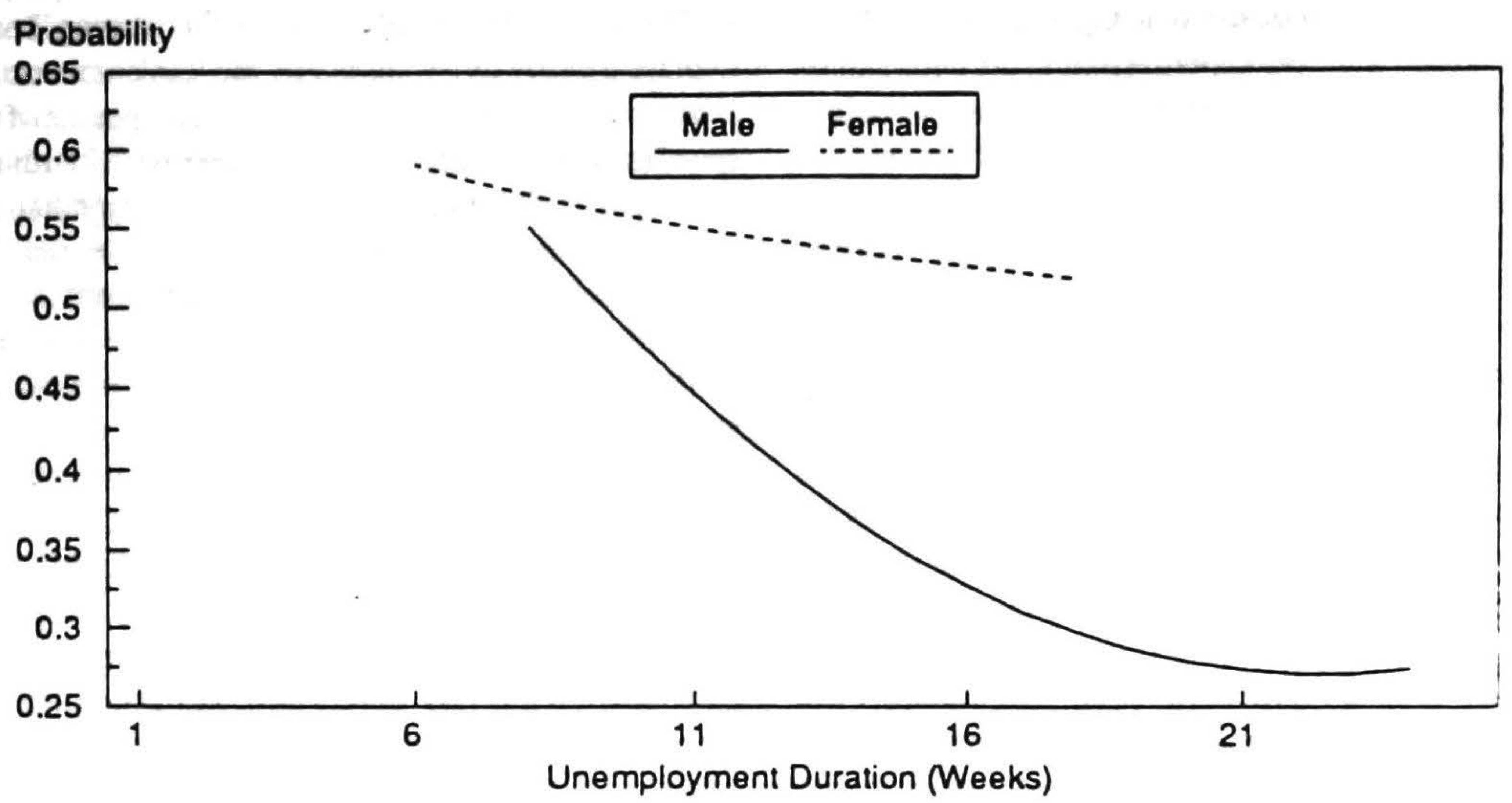

Figure 3. Probability of exit from unemployment to labour force periphery hazard functions

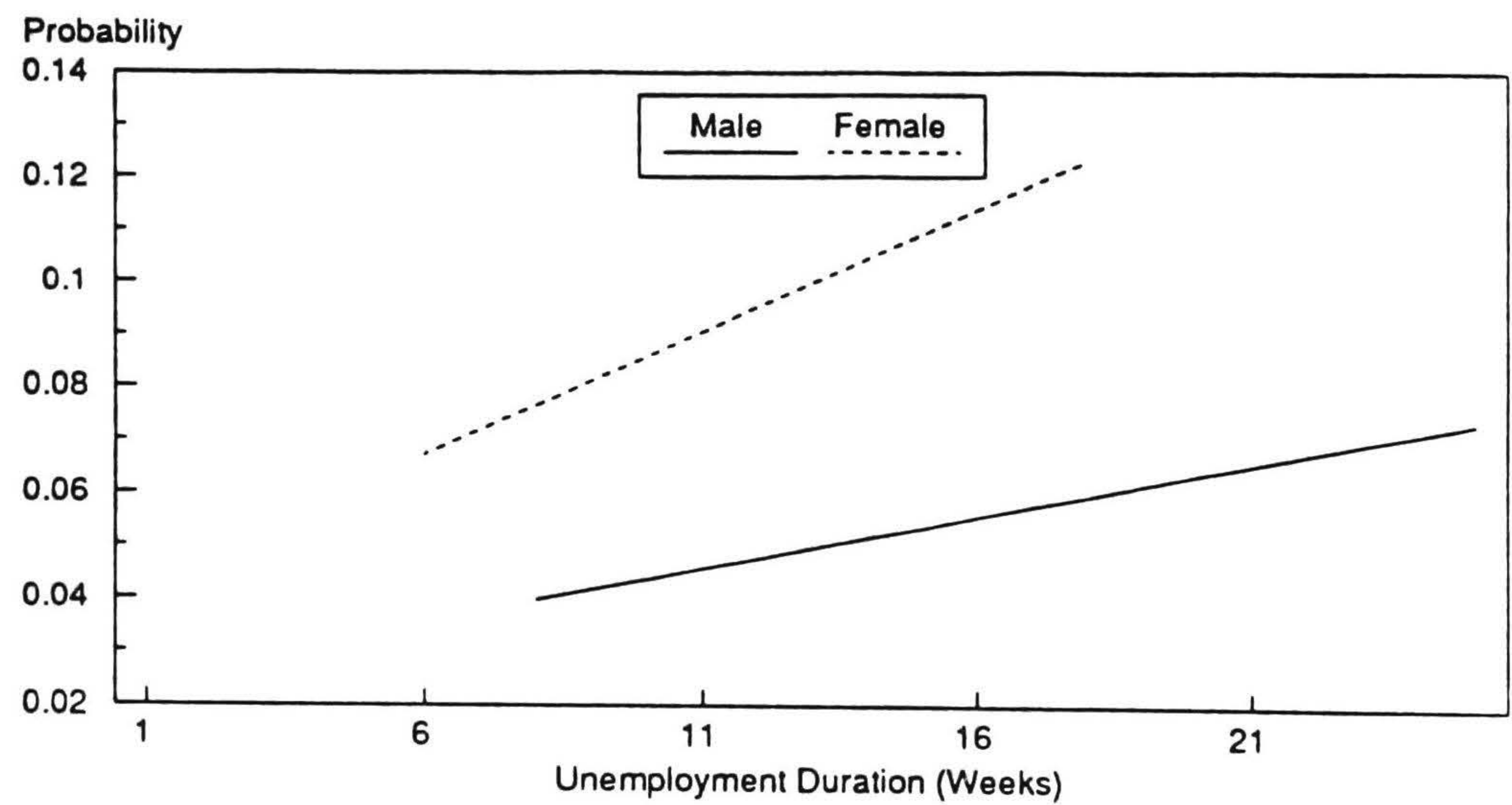

Figure 4. Probability of exit from unemployment out of the labour force hazard functions

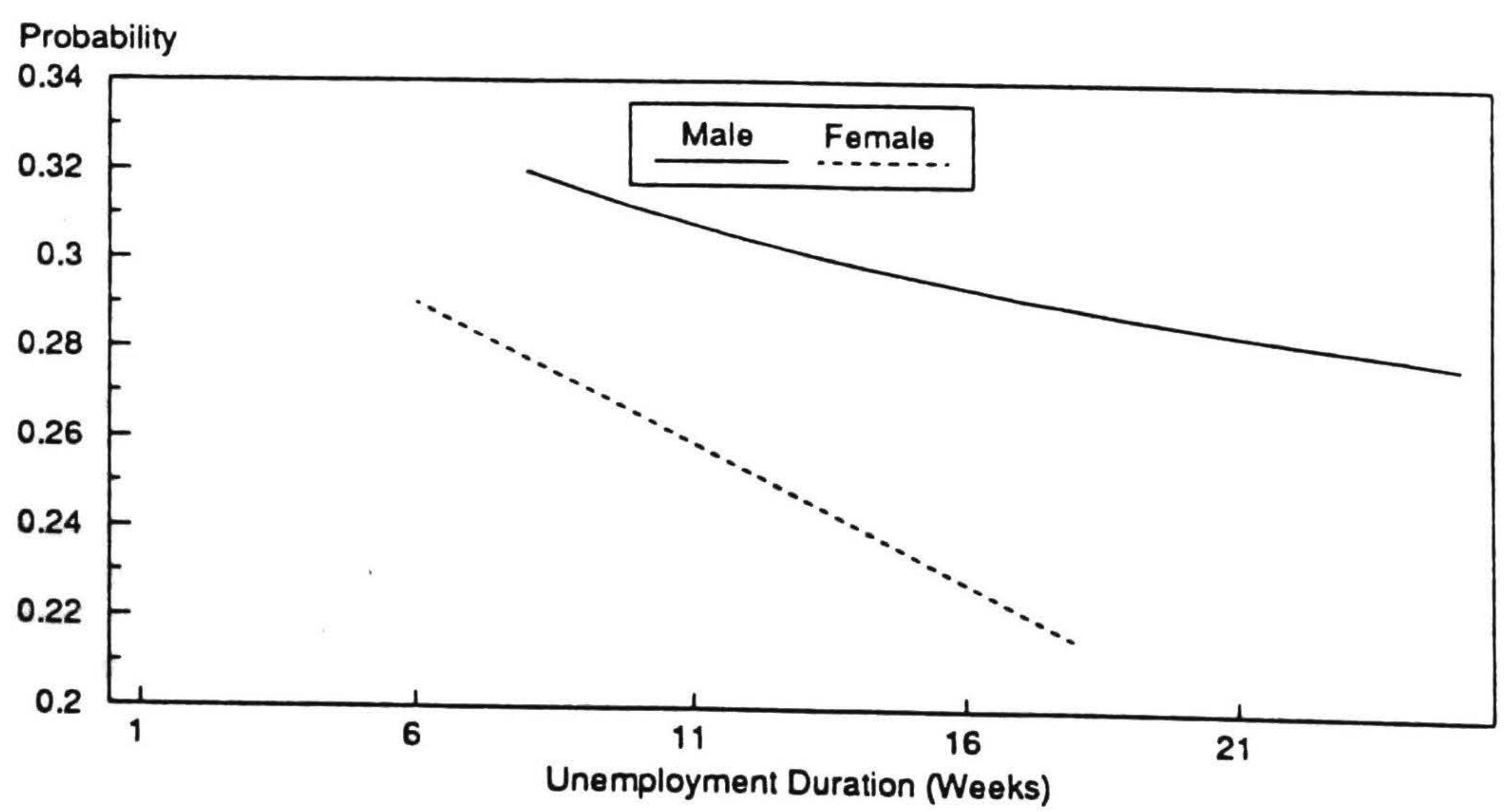


between the probability of exit from unemployment and the length of unemployment spells, it needs stressing that these correlations are not evidence of any causal relationships. We can not say that higher exit probability leads to a change in duration or that longer duration causes a change in exit probability - it may be that factors that lead to a change in one also lead to a change in the other.

The functional forms graphed have been truncated to only illustrate the relationships within the experience domain of the data. This is done because extrapolations on either side of these ranges may be unrealistic as they merely represent the best fit of a limited number of functional forms tested. As demonstrated in Figure 1, the median unemployment duration was between 8 and 25 weeks for men and between 6 and 18 weeks for women over the estimation period.

Limitations of the functional forms tested are most obvious with the male $u e$ hazard function graphed in Figure 2. The preferred hazard function is a quadratic with a negative linear term. This provides the best fit over the 1986-91 data set, but produces unrealistic results if the median unemployment duration for men were higher or lower than experienced in the estimation period. For example the equation implies that as median duration increases ue will eventually exceed 1 (from the 45 th week on) which is an infeasible result with probabilities. This would suggest that although the quadratic form provides the best fit (of the functional forms tested) over the estimation period, it still only provides a rough approximation of any relation.

\section{Discussion}

Having noted these factors it would appear that as unemployment duration increases the probability of finding employment decreases, but at a diminishing rate. The negative relationship is initially stronger for men, but there appears to be a lower limit to ue around the 0.25 mark which is reached when median unemployment duration exceeds twenty weeks. Given the limitations of the experience domain, the number of observations in the data set and the functional forms tested we can not put strong credence in the reversal in the relationship beyond the 22 week mark implied by the hazard function.

This evidence supports, but does not prove, the view that increasing lengths of unemployment spells reduces employability. It conforms with views that the long term unemployed are not viewed favourably by potential employers and/or that job search intensity falls as success continues to elude unemployed individuals. If this is the case, then this evidence also suggests that the marginal declines in employability diminish with increasing unemployment duration and might approach some limit. That is, the employability of individuals after one month unemployment may be quite a bit stronger than their employability after six months, but there may be little difference in their employability after 12 or 18 months unemployment.

The less negative relationship for women compared with men might be explained by the less career orientated jobs pursued by women and a greater acceptance of women spending time out of employment compared with men. In $199135.8 \%$ of employed females were designated as parttime in the HLFS compared with $10.1 \%$ for men. Greater willingness to take up part-time jobs increased the relative number of job opportunities for women as this was the area of strongest job growth: while full-time employment for women declined by $11.0 \%$ between 1986 and 1991 , female part-time employment grew by $18.4 \%$. A lower proportion of working age women participate in the labour force: averaging $54.2 \%$ in 1991 compared with $73.6 \%$ for men. This may mean that more women are likely to opt for jobs where experience is less important and hence duration of unemployment is less critical to potential employers. The higher proportion of women outside the labour force may also mean it is easier for women to avoid any stigma that might be associated with long-term unemployment.

These arguments could be countered by the view that the statistical relationships presented are tautological in the sense that as the ability to find jobs declines then so too will the ability to leave unemployment and hence unemployment durations will increase. Although there may be some basis to this argument, the coincident sharp increase in the proportion of long term unemployed suggests that it has been harder for the longer term unemployed to find employment. That is the increase in unemployment did not necessitate the increase in unemployment duration that occurred.

A more plausible counter argument is that the increase in unemployment resulted in an increasing proportion of the unemployed being of the type that were not highly employable and hence tended to be unemployed for longer periods of time. That is, the apparent negative relationship between ue and unemployment duration is not due to any direct relationship between the two, but because of the types of people who are swelling the ranks of the unemployed.6

Figure 3 indicates a positive linear relationship between unemployment duration and up. Women are more likely to leave unemployment for the labour force periphery and this probability increases faster as duration increases (as indicated by the steeper sloped hazard function in Figure 3 ). The positive relationship could be argued to represent a discouragement impact of increasing periods of unemployment. Greater female discouragement could reflect a lower attachment to the labour force and paid employment. It could also represent a more active utilisation of unpaid periods. For example, women might be more likely to take part in voluntary activities when unemployed which might make them unavailable immediately for paid employment (and hence of ficially outside the unemployed category). 
In contrast to the positive relationship with $u p$, unemployment duration has a negative relationship with un, see Figure 4. This negative relationship might represent institutional lock-in effects: income support from unemployment benefits might encourage activities that maintain eligibility and hence unemployment classification. The more negative relationship for women might reflect a dualistic attitude of women to employment. As demonstrated in Grimmond (1992, Table 3.6) there is a far greater likelihood of women to shift between employment and out of the labour force than between employment and unemployment. Therefore it may be that the subset of women who do shift into unemployment tend to be more committed to labour market participation than is the case for the female population in general. This could explain why unemployed women seem to be more willing than the average unemployed male to persist in unemployment rather than leave the labour force.

\section{Extensions}

As stated earlier, the use of the median measures of unemployment duration in the above analysis ignores information about the spread of the unemployed accross duration intervals. Mean measurements would take into account some of this information but, like the median approach, it largely ignores distribution and the experience of individuals in the distribution tails can only be estimated through extrapolation. As demonstrated in the ue hazard function for men this extrapolation can have unsatisfactory results.

A more direct approach has been attempted to overcome these problems. The same probability of exit dependent variables: ue, up and un, are regressed on explanatory variables that measure the proportion of unemployed that continue to remain unemployed from the previous survey. The quarterly survey intervals and the duration data published meant that three duration variables could be calculated:

-the proportion of newly unemployed in the previous quarter that remain unemployed this quarter

$$
\text { (U3 }-6, \mathrm{t}^{\mathrm{U}} \mathrm{U-3, \textrm {t } - 1} \text { ), }
$$

-the proportion of those unemployed for at least three months that remain unemployed for six to twelve months

$$
\left(U_{6-12, t} /\left[U_{3-6, t-2}+U_{3-6, t-1}\right]\right) \text {, }
$$

-the proportion of those unemployed for at least six months that remain unemployed for over twelve months

$$
\left(\left(U_{>12, t}\left\{\left[U_{6-12, t-2}+U_{6-12, t-1}\right]\right)\right.\right. \text {. }
$$

The two quarter denominators of the longer duration variables are an attempt to reduce potential bias associated with the single six to twelve month duration interval collected in the HLFS. This duration interval is longer than the gap between surveys so we are unable to accurately gauge the numbers shifting between intervals in consecutive surveys.

Regression results, presented in Table 3, generally conform with those generated by hazard functions: unemployment duration has the strongest relation with ue which tends to be negative, the relation with up is weaker and positive, and what relation with un that can be found is negative. This analysis does provide some further insights, however.

-it appears that it the greater than six month unemployment duration group that have the strong negative relation with ue,

-with women a significant relationship with ue does not eventuate until beyond twelve months unemployment,

-the negative ue-duration relation for males does not reverse as suggested by the hazard functions, but the coefficient for the over twelve months duration is only slightly more negative than the six to twelve month coefficient.

-as with the hazard functions the positive up-duration relation is stronger for women, but only becomes significant after twelve months unemployment,

-there was less evidence of a un-duration relation, with only the aggregate data showing a significant relation, and only in the three to six month duration interval.

\section{Conclusions}

The combination of these results suggest the following conclusions from the analysis:

- there does appear to be a negative relation between probability of leaving unemployment for employment and duration of unemployment.

- this negative relationship has been stronger with men and apparent after shorter spells of unemployment.

- there is evidence of a positive relation between the probability of moving to the labour force periphery and unemployment duration, this relation is stronger with women but does not seem to manifest itself until after lengthy periods of unemployment,

- there is some evidence of a negative relation between the probability of leaving the labour force and unemployment duration, but this seems to occur only in the first six months of unemployment,

-the evidence does not resolve whether there is any causation in these relationships or whether there are external factors that lead to these simultaneous events, eg a dominance of people within the unemployed who exhibit low employability traits - a distinction between these factors would be a desirable area of future research.

\section{Future Research}

The work documented here is just an initial look at factors affecting unemployment duration in New Zealand. To aid the design and implementation of effective policies aimed at reducing imperfections in the new Zealand labour market (implied by the growth in longterm unemployment in 
Table 3. Results of regressing probability of eExit from unemployment on proportions remaining in unemployment 1986:3 - 1991:2

Dependent Variable : ue

\section{Explanatory \\ Variables}

Constant

3-6 Months

6-12 Months

$>12$ Months

$\mathrm{R}^{2}$

DW

Dependent Variable: up

Explanatory
Variables

Constant

3-6 Months

6-12 Months

$>12$ Months

$R^{2}$

DW

Dependent variable un

\section{Explanatory}

Variahles

Constant

3-6 Months

6-12 Months

$>12$ Months

$\mathbf{R}^{2}$

DW

standard errors in brackets, * indicates significant at the $95 \%$ level of confidence

\section{Total}

0.330

$(0.040)$

$-0.401 *$

$(0.160)$

0.039

$(0.061)$

$-0.003$

$(0.083)$

0.597

2.192

\section{Male}

$0.303^{\star}$

(0.053)

$-0.126$

(0.148)

$-0.071$

$(0.064)$

$-0.092$

(0.086)

0.410

1.952

$\begin{array}{ccc}\text { Total } & \text { Male } & \text { Female } \\ 0.583^{*} & 0.630^{*} & 0.571^{*} \\ (0.036) & (0.047) & (0.068)\end{array}$

$\begin{array}{ccc}0.346^{*} & 0.027 & -0.109 \\ (0.141) & (0.130) & (0.225)\end{array}$

$-0.269^{*}$

(0.054)

$-0.254^{*}$

(0.056)

$-0.168$

(0.145)

$-0.311^{*}$

(0.075)

$-0.250^{*}$

(0.103)

0.899

1.374

0.830

0.566

1.391

1.306

Total

Male

Female

0.021

(0.021)

0.009

(0.024)

0.009

(0.034)

0.061
$(0.083)$

0.023

0.085

(0.068)

(0.112)

$-0.028$

(0.032)

$-0.006$

$(0.029)$

0.018

(0.072)

$0.095^{*}$

(0.043)

$0.082^{*}$

(0.039)

$0.116^{*}$

(0.052)

0.648

0.463

0.500

1.693

2.253
Female

0.257 *

(0.052)

$-0.170$

(0.173)

0.207

(0.111)

$-0.149$

(0.079)

0.390 
recent years) it would be useful to accurately quantify the relative importance of factors that influence unemployment duration. For example, if unemployment duration does have a strong and direct negative influence on a person's ability to find employment, then job creation/subsidisation might be a worthwhile area for policy emphasis. On the other hand inappropriate skills might be more important, suggesting resources devoted to training may be more effective. To obtain an accurate picture, one needs to isolate the marginal influences of employment characteristics on the employability of individuals. Modelling the probability of leaving unemployment using individual employment histories from the HLFS would seem to be a promising approach for obtaining such information.

\section{Notes}

1 The presented paper represents part of a larger study of labour force dynamics in New Zealand funded by the Foundation for Research, Science and Technology, and completed while I was a research economist at the NZ Institute of Economic Research. I would like to thank John Savage who initiated and planned most of this study. Opinions expressed in this paper are of course my own and should not be regarded as reflecting those of the Foundation, the NZIER, or my current employers, the Treasury.

2 However, high relative levels of government support for the unemployed could perhaps encourage long periods of voluntary unemployment in some cases.

3 Unemployment duration data used in this section comes from published HLFS data derived from recall questions in the survey questionnaire. Lack of definitional control and potential bias in responses may distort data generated using recall methods. But the recall unemployment duration data used is presently the only New Zealand data set available for current purposes. The published data is disaggregated by gender only. A future development would be to extract duration data by other labour market segmentation criteria, eg age, qualification, ethnicity etc.

4 Not in the labour force would then be defined as the working age population less those employed, unemployed and in the peripheral labour force.

5 By the averaging process, the total hazard functions lie between those established for males and females. They have been omitted for presentational purposes and as they do not add significantly to the discussion.

6 An examination of factors that are likely to encourage longer periods of unemployment are examined in section 4.2 of Grimmond (1992), but a true separation of such factors from duration effects requires the use of a more sophisticated approach than used there. Instead techniques such as those employed by Narendranathan and Stewart (1989) utilising individual employment histories are required.

\section{References}

Clark K B and Summers L H (1979) Labor Market Dynamics and Unemployment: A Reconsideration, Brookings Papers on Economic Activity, 1, pp1360

Dasgupta A (1991) Measuring Unemployment, University of Otago, Economics Discussion Papers, No 9118

Grimmond D (1992) An Examination of Labour Force Dynamics in New Zealand with an Emphasis on Unemployment Duration, NZIER, Forthcoming

Hasan A and de Broucker P (1982) Duration and Concentration of Unemployment. Canadian Journal of Economics, Vol XV No 4. pp735-756

Kay L B (1982) Using Business Opinion Uultsuon of Capacity, Quarterly Survey of Business Opınıon. NZIER, December, pp 2-8

Keifer N M (1988) Economic Duration Data and Hazard Functions, Journal of Economic Literature. Vol XXVI No 2, pp649-679

Morrison P S (1989) Labour Adjustment in Metropolitan Regions, VUW Press for Institute of Policy Studies: Wellington

Narendranathan W and Stewart M B (1989) Modelling the Probability of Leaving Unemployment: Competing Risks Models with Flexible Baseline Hazards, Warwick Economic Research Papers, No 331

Perry G L (1972) Unemployment Flows in the US Labor Market, Brookings Papers on Economic Activity, 2, pp245-278 